\title{
Genesis of initial defects in the process of monocrystalline silicon oxidation with subsequent scribing
}

\author{
V.A. Smyntyna and O.V. Sviridova \\ I.I. Mechnikov Odessa National University, \\ 42, Paster str., 65082 Odessa, Ukraine \\ Corresponding author e-mail: sviridova@onu.edu.ua
}

\begin{abstract}
The type, density, and distribution of defects in initial and oxidated monocrystalline silicon wafers were studied by modern methods. It was established that disordered silicon and stacking faults are basic defects in near-surface layers of oxidated monocrystalline silicon. It was shown that stacking faults are generated during the oxidation process, and the mechanism of their formation is connected with the defective layered structure of initial silicon wafers. It was established that defects of layered heterogeneity, on the one hand, lead to the formation of stacking faults and, on the other hand, prevent their propagation to the wafer bulk.
\end{abstract}

Keywords: layered heterogeneity, stacking fault, dendrites, swirl defects, dislocations.

Manuscript received 07.08.09; accepted for publication 22.10.09; published online 30.12.09.

\section{Introduction}

Layered silicon dioxide - silicon structures that are used in current integrated electronics are of special interest, since it allows formation of the built-in induced barrier areas on interfaces of these structures. These areas are widely used to study semiconductors, dielectric phases, and interfaces. Parameters of initial semiconductor, dielectric materials and their interfaces, as well as their deficiency influence electrophysical parameters of instrumentation $[1,2]$. The contribution to device deficiency caused by slicing the initial nonoxidated and oxidated wafers should also be taken into account. More and more rigid requirements on reliability of parameters of structures and systems on their basis demand not only new technologies, but also further experimental and theoretical researches of defect formation processes. As a result, quality assurance efficiency of produced structures can be increased [3]. Such researches are necessary, in particular, to increase reliability and stability of parameters of silicon field MOS-structures [2].

Silicon oxidation process results both in generation of new defects and in genesis of initial defects. If the new defect generation process during silicon oxidation is studied well enough [4], the question of genesis of initial defects is still the open one [5].
Thus, in this work we report results of investigations devoted to genesis of initial defects in the process of silicon oxidation and subsequent machining (scribing) of oxidated silicon.

\section{Samples and experimental techniques}

Monocrystalline phosphorous-doped silicon (PDS) wafers PDS-4.5 (111), nonoxidated and oxidated at temperatures close to $1150{ }^{\circ} \mathrm{C}$ in atmosphere of dry oxygen were studied. The diameter of wafers was $40 \mathrm{~mm}$, thickness of silicon dioxide $\left(\mathrm{SiO}_{2}\right)$ was $(1 \pm 0.1) \mu \mathrm{m}$. Detection of defects was carried out after processing of silicon wafer surface in Sirtle chemical selective etchant [6]. Silicon dioxide was preliminary removed in hydrofluoric acid (HF). Sirtle chemical selective etchant $\left(50 \mathrm{~g} \mathrm{CrO}_{3}+100 \mathrm{ml} \mathrm{H}_{2} \mathrm{O}+100 \mathrm{ml} \mathrm{HF}\right.$ $(46 \%))$ is used to etch close-packed silicon planes (111) with the etching speed of about (2-3) $\mu \mathrm{m} / \mathrm{min}$. Setting the etching time from $10 \mathrm{~s}$ with a step of $10 \mathrm{~s}$, the levelby-level analysis of the silicon wafer was carried out. Knowledge of the etching speed enabled us to control the depth of analysis from the surface into the bulk of the silicon wafer. Scanning electron microscopy of surface (SEMS) by scanning electron microscope "РЭМ 106Л" manufactured by SELMI with X-ray microanalyzer (sensitivity of the device reaches 


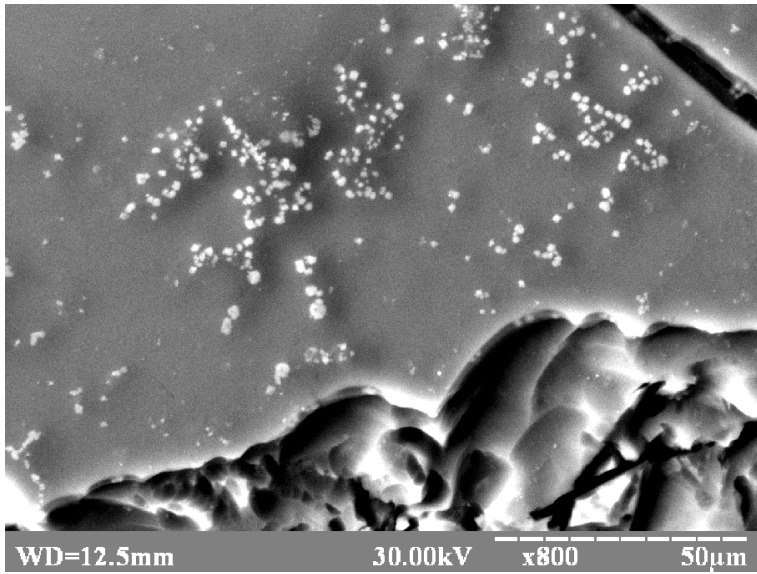

Fig. 1. SEMS image of the end face of (111) silicon wafers investigated. Etching time $-100 \mathrm{~s}$. The layered wafer structure and clusters of background impurity are observed.

0.5 at.\%) and also by scanning electron microscope manufactured by OXFORD INSTRUMENTS with the adapter for X-ray microanalysis (sensitivity of the device is not worse than 0.02 at.\%) were used for studying of silicon surface after chemical treatments $[7,8]$.

\section{Results and discussion}

Research of the end face of silicon wafers before oxidation by means of SEMS has revealed the presence of the defect with layered heterogeneity. The mechanism of its occurrence is related with imperfection of growing silicon ingots and is not related with the oxidation process (Fig. 1). Cluster aggregates of background impurity atoms (Fig. 1) and microdefects (Fig. 2) were detected in silicon wafers before oxidation.

After removal of $\mathrm{SiO}_{2}$ in $\mathrm{HF}$, usual structural defects in silicon (such as dislocations or stacking faults) were not found directly under silicon dioxide in oxidated silicon wafers. These structural defects were not also observed in the layers, which lay at the depths $0.4,0.8$, and $1.3 \mu \mathrm{m}$ under the surface of the silicon wafer (etching time was 10, 20, and $30 \mathrm{~s}$, respectively). Absence of usual defect pattern in near-surface layers of silicon indicates that these layers contain strongly disordered silicon, similar to a fine-blocked polysilicon [9]. It was established that structural defects are not observed in disordered silicon layer by SEMS, because the surface of disordered silicon layer is highly charged, and that blocks reflected electron beam [10]. We observed etching pits of irregular shape, connected with areas of removed silicon oxide, formed owing to accelerated diffusion of oxygen along initial structural defects during oxidation. Further level-by-level analysis of silicon wafers has shown that disordered silicon layer passes in the layers, containing grids of dislocations, and then in the layers containing oxidation stacking faults and separate dislocations (Fig. 3). The level-by-level

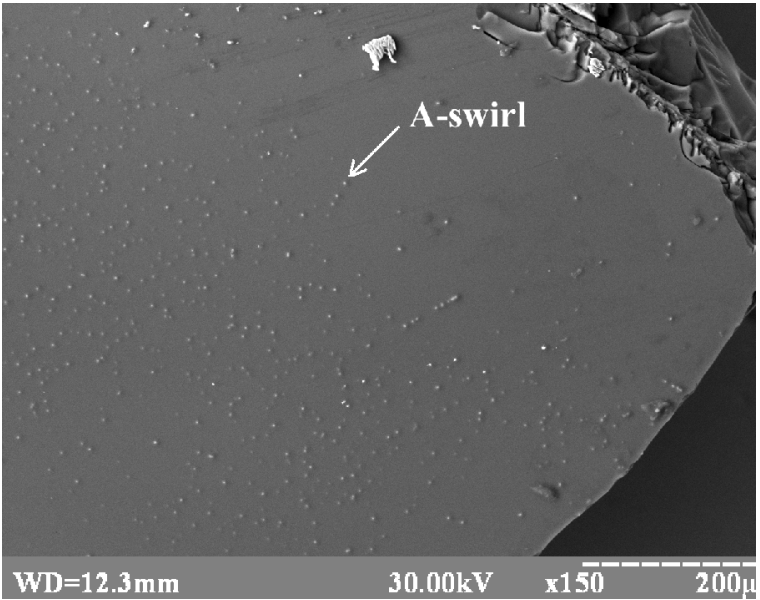

Fig. 2. SEMS image of the fragment of the swirl picture formed by A-type microdefects on the nonoxidated (111) silicon wafer surface. Etching time - 120 s.

analysis of nonoxidated silicon wafers has not revealed stacking faults. The high density of dislocations and lines of dislocations is observed in the locations of stacking faults in oxidated wafers. The fragment of such dislocation cluster is presented in Fig. 4. It was established that stacking faults and dislocation clusters in oxidated silicon wafers are formed in locations of Atype microdefect clusters in initial wafers.

Stacking faults, atypical at the first sight, were found out in silicon wafers with (111)-orientated surface plane. Crystallographic etched pits of these stacking faults look not as a straight line but represent the closed and non-closed triangles (Fig. 3). These patterns represent combinations of two (Fig. 5), or three (Fig. 6) stacking faults that could not develop after striking with the boundary formed by the neighbouring stacking fault.

As the analysis of wafers has not revealed any traces of mechanical damages of a surface, existence of stacking faults can be explained exclusively with the presence of swirl defects. According to one of the existing models [11,12], complexes of point defects and background impurity lead to formation of swirl defects. Therefore, the cluster of background impurity, caused by imperfection of technological process of silicon ingots growth, has led to the formation of point defects that, in turn, have led to formation of swirl defects. Swirl defects, at the absence of mechanical damages, are the only reason of stacking faults formation during hightemperature silicon oxidation. Owing to defect of layered heterogeneity and swirl distribution of A-type microdefects, the revealed stacking faults are observed only for separate areas of separate silicon layers, that, as a whole, does not lead to essential changes in electrophysical parameters of silicon wafers. Therefore, stacking faults are observed not on the whole surface of silicon layer but only on some separate areas [13] and do not lead to considerable changes in electrophysical parameters of silicon. 


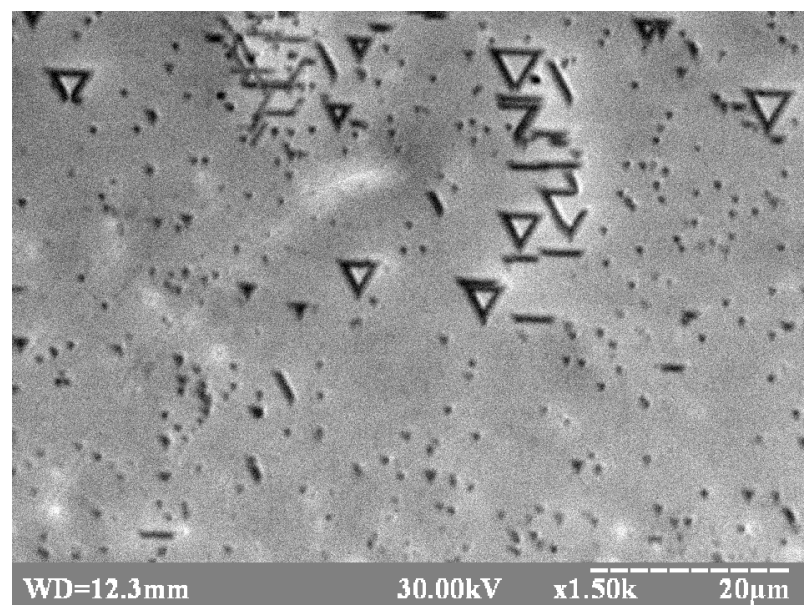

Fig. 3. SEMS image of dislocations and stacking faults on the oxidated (111) silicon wafer surface under silicon dioxide. Etching time $-60 \mathrm{~s}$.

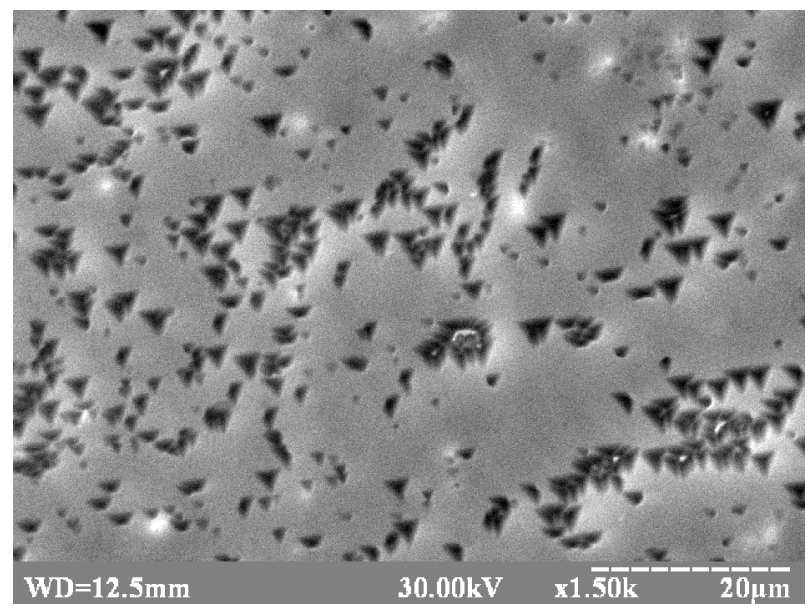

Fig. 4. SEMS image of a dislocation bunch on the (111) silicon wafer surface under silicon dioxide. Etching time $-80 \mathrm{~s}$.

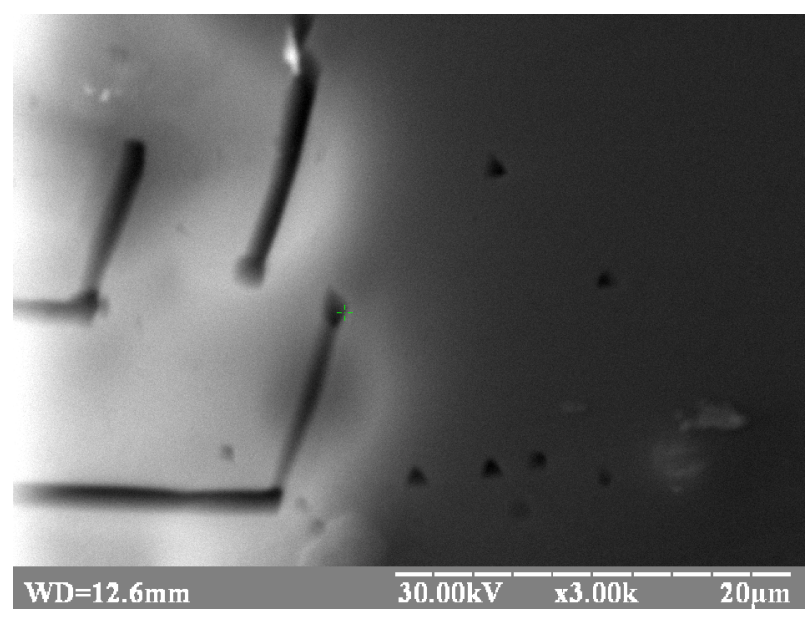

Fig. 5. SEMS image of dislocations, single stacking fault, and two pairs of united stacking faults on the surface (111) of silicon wafer edge under silicon dioxide. Etching time $-70 \mathrm{~s}$.

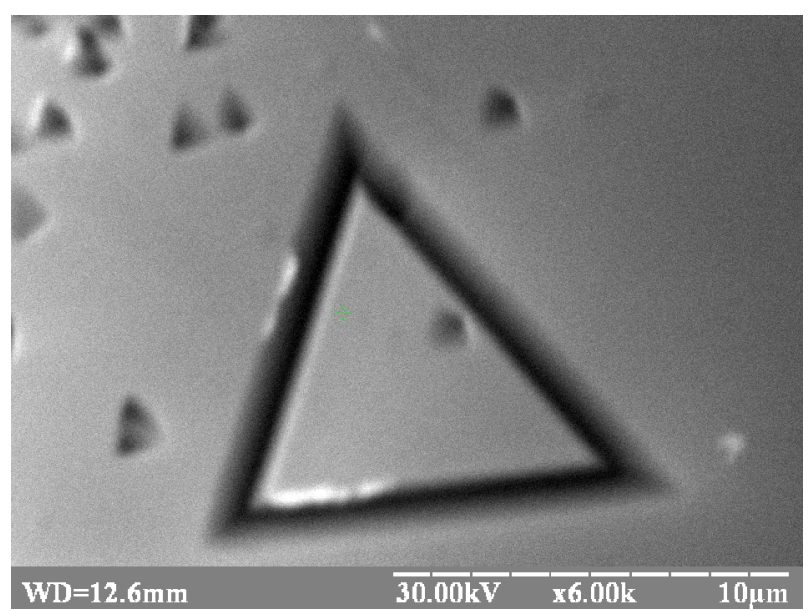

Fig. 6. SEMS image of dislocations and three, limited by each other in their development oxidation stacking faults on the (111) surface of silicon wafer under silicon dioxide. Dislocation is observed inside a triangle, formed by stacking faults. Etching time is $70 \mathrm{~s}$.

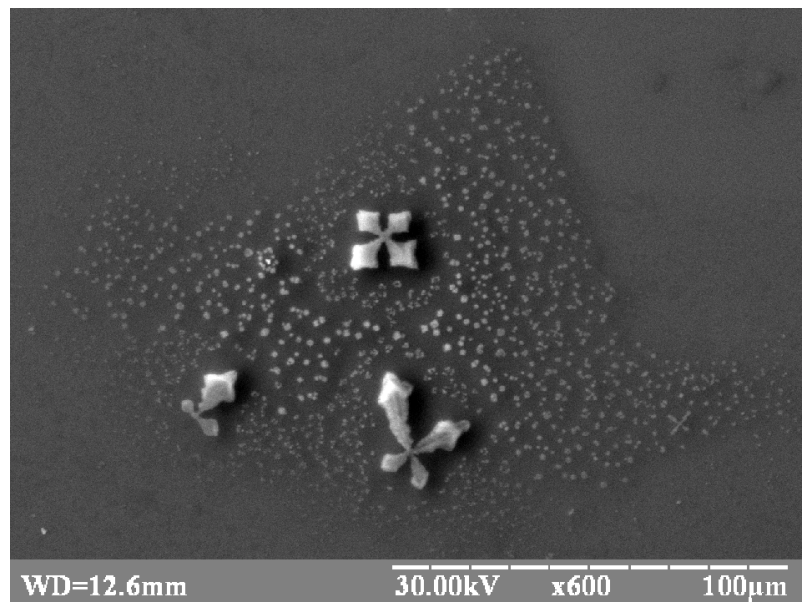

Fig. 7. SEMS image of dendrites on the (111) surface of oxidated silicon wafer under silicon dioxide. Etching time is $100 \mathrm{~s}$.

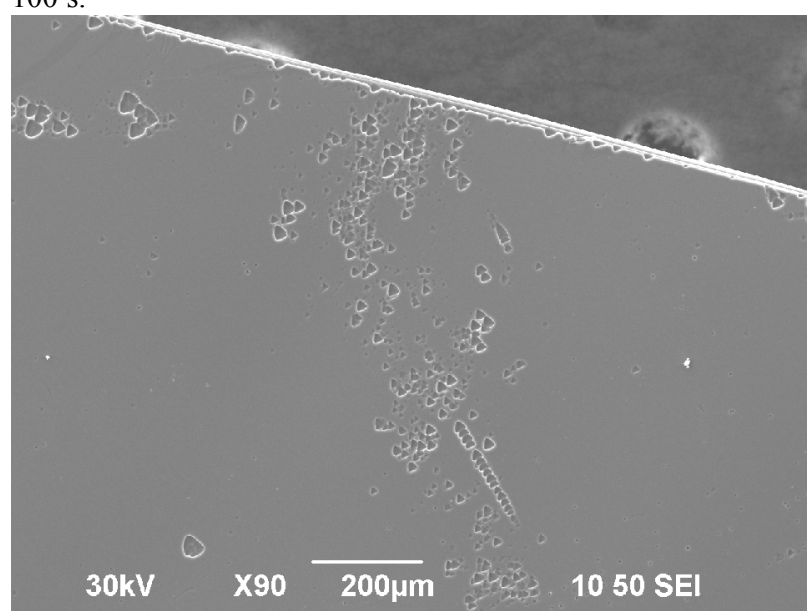

Fig. 8. SEMS image of separate dislocations and lines of dislocations on the (111) surface of silicon wafer under silicon dioxide. Etching time is $4 \mathrm{~min}$. 
Impurities in silicon (Fig. 1) can form macrodefects in a form of dendritic formations (Fig. 7) that consist of a mixture of solid solutions of iron and chrome. Accumulation of mechanical stresses, which can exceed silicon yield stress, takes place on dendrite-silicon boundary $[14,15]$. Thus, the area of strongly disordered silicon is formed directly under the dendrite.

The case of dislocation multiplication when scribing the oxidated silicon wafer is presented in Fig. 8 . The depth of analysis was $10 \mu \mathrm{m}$. Dislocations and lines of dislocations are caused by Frank-Read and Alexander-Haasen sources [16]. It is seen that mechanical stresses propagate in a radial direction from the scribing line. Dislocations and areas with changed mechanical potential are located in the same direction. These areas can be related with the existence of FrankRead sources, that is, with the existence of point defects of different types, which locally change elastic parameters of crystals, which leads to formation of structural defects under external actions [17]. Within the limits of Alexander-Haasen model, it is supposed that dislocation multiplication occurs by their creep with further multiplication.

\section{Conclusion}

1. Layering of oxidated wafers structure results in accumulation of all foreign impurities on layer boundaries of monocrystalline silicon. The layer boundary, in fact, is a surface. The surface, in turn, is always a drain area for point defects. Point defects act as sources of microdefects, such as, in our case, A-type swirl defects. At wafer oxidation, swirl defects are sources of stacking faults. This can be explained by the fact that swirl defects are always decorated by a background impurity. As a result, mechanical stresses arise at the interface of silicon and impurity, decorating microdefect, which can exceed yield stress. It leads to the accelerated oxygen diffusion with formation of oxidation stacking faults. Thus, it may be concluded that owing to wafer layering, areas of swirl defects are formed at layer boundaries in locations of foreign impurity clusters. When wafer is oxidated, swirl defects transform to stacking faults. That is, layering of monocrystalline silicon wafer is the reason for stacking faults appearance in oxidated wafers. The mechanism of stacking faults formation from microdefects because of wafer oxidation is proposed.

2. Owing to layered wafer structure, structural defects (stacking faults), observed for each of wafer layers, do not intergrow over the whole wafer thickness, but begin and end within the limits of one layer. Thus, wafer layering leads to the decrease of the bulk density of defects, inhibiting their intergrow over the wafer thickness.

3. For technological processes related with silicon oxidation the layered wafers can be recommended as the structures containing drain areas for foreign impurities on the one hand, and as the structures blocking growth of structural defects (such as stacking faults and dislocations) when oxidating and scribing these wafers, on the other hand.

\section{References}

1. T.F. Ciszek, T.H. Wang, Silicon float-zone crystal growth as a tool for the study of defects and impurities // Electrochemical Society Fall Conference. October 22-27, 2000, Phoenix, Arizona, p. 1-15.

2. Kwang $\mathrm{Su}$ Choe, Byung Nam Jang, Minoritycarrier lifetime optimization in silicon MOS devices by intrinsic gettering // J. Cryst. Growth 218, p. 239-244 (2000).

3. Th. Wetzel, J. Virbulis, Modeling in industrial silicon wafer manufacturing - from crystal growth to device processes // Intern. Scientific Colloquium Modeling for Electromagnetic Processing. March 24-26, 2003, Hannover, p. 67-72.

4. O. Sviridova, Reasons of dislocation and stacking fault appearance and annihilation in oxidated silicon wafers // Intern. students and young scientists' conference in theoretical and experimental physics HEUREKA-2009. May 20-22, 2009, Lviv, Ukraine, p. C38 (in Ukrainian).

5. V.I. Talanin, I.E. Talanin, Recombination parameters of intrinsic point defects in dislocationfree silicon monocrystals // Skladni systemy $i$ procesy No. 1, p. 21-31 (2005) (in Ukrainian).

6. E. Sirtle, A. Adler, Chromsaure-FlUssaure als specifisches System zur Atzgrubenentwicklung auf Silizium // Z. Metallik.52(8), S. 529-531 (1961).

7. J.I. Goldstein, D.E. Newbury, P. Echlin et al., Scanning Electron Microscopy and X-Ray Microanalysis. Book 1. Mir, Moscow, 1984 (in Russian).

8. J.I. Goldstein, D.E. Newbury, P. Echlin et al., Scanning Electron Microscopy and X-Ray Microanalysis. Book 2. Mir, Moscow, 1984 (in Russian).

9. O.A. Kulinich, M.A. Glauberman, N.N. Sadova, Investigation of near-surface layers in $\mathrm{SiO}_{2}-\mathrm{Si}$ structures // Izvestiya VUZov. Fizika No. 10, p. 6366 (2003) (in Russian).

10. V. A. Smyntyna, O.A. Kulinich, M.A. Glauberman, G.G. Chemeresyuk, I.R. Yatsunskiy, O.V. Sviridova, Technique for oxidation parameters definition, based on investigation of defects formation patterns in silicon inversion MOS-structures // 17-th Intern. Crimea conference CriMiCo2007. September 1014, 2007, Sebastopol, Crimea, Ukraine, p. 556-557 (in Russian).

11. I.V. Vemer, N.N. Gerasimenko, Y. Zhang, J.W. Corbett, Evolution of point defects during swirl formation in semiconductors // Materials Letters $\mathbf{1 5}$ $(5,6)$, p. 347-352 (1993).

12. T.W. Fan, J.J. Qian, J. Wu, L.Y. Lin, J. Yuan, Tentative analysis of Swirl defects in silicon crystals // J. Cryst. Growth 213, p. 276-282 (2000). 
13. J. Fukuda, T. Iwasaki, M. Tanaka et al., Microfluctuation of Growth Rate and Grown-in Defect Distribution in CZ-Si // Nippon Steel Technical Report No. 83, p. 54-60 (2001).

14. V.A. Smyntyna, O.V. Sviridova, Influence of initial defects on defect formation process in ion doped silicon // Semiconductor Physics, Quantum Electronics \& Optoelectronics 12 (2) p. 110-115 (2009).

15. V.A. Smyntyna, O.A. Kulinich, O.V. Sviridova, M.A. Glauberman, Yield stress in semiconductor silicon. Factors of influencing // Fizyka Khimiya Tverdogo Tila 10 (2), (2009) (in Ukrainian).

16. O.V. Sviridova, Reasons for yield stress reduction at scribing of oxidated monocrystalline silicon wafers // 13-th Intern. youth forum "Radioelectronics and youth in XXI century". March 30-April 1, 2009, Kharkov, Ukraine, p. 300 (in Russian).

17. M.G.Milvidsky, B.V.Osvensky, Structural Defects in Monocrystals of Semiconductors. Metallurgy, Moscow, 1984 (in Russian). 